\title{
Chronic stress has lasting effects on improved cued discrimination early in extinction
}

\author{
Jessica M. Judd, Elliot A. Smith, Jinah Kim, Vrishti Shah, Federico Sanabria, \\ and Cheryl D. Conrad \\ Department of Psychology, Arizona State University, Tempe, Arizona 85287-1104, USA
}

\begin{abstract}
Chronic stress typically leads to deficits in fear extinction when tested soon after chronic stress ends. Given the importance of extinction in updating fear memories, the current study examined whether fear extinction was impaired in rats that were chronically stressed and then given a break from the end of chronic stress to the start of fear conditioning and extinction. Male rats were chronically stressed by restraint $(6 \mathrm{~h} / \mathrm{d} / 21 \mathrm{~d})$ and tested soon (termed immediate, STR-IMM), or 3 or $6 \mathrm{wk}$ after a rest period from restraint (termed rest or "R," STR-R3, STR-R6). In Experiment 1, STR-R3 and STR-R6 discriminated between the cue and nonshock context better than STR-IMM or control. Interestingly, STR-IMM showed high freezing to the nonshock context. Consequently, Experiment 2 investigated whether STR-IMM generalized across contexts, which was not supported. Experiment 3 determined whether STR-IMM were susceptible to second-order conditioning to a novel context, but showed that the level of second-order conditioning was similar for all groups. These findings reveal that rats exposed to chronic stress and then given a rest period of 3 or $6 \mathrm{wk}$, express unique fear extinction profiles compared to control and STR-IMM. Specifically, STR-R demonstrated excellent cue and context discrimination during extinction, and perhaps showed a stress inoculation effect. For STR-IMM, the heightened freezing under these extensive acclimation parameters was not attributed to generalization nor to second-order fear conditioning to "safe" contexts and, instead, may reflect hypervigilance.
\end{abstract}

[Supplemental material is available for this article.]

Posttraumatic stress disorder (PTSD) affects 6\%-9\% of the U.S. population and nearly $40 \%$ of those exposed to extreme trauma, such as combat veterans (Hoge and Warner 2014; Sareen 2014). PTSD is characterized by persistent memories of the traumatic event, avoidance of potential triggers for memories of the traumatic event, and hyperarousal (American Psychiatric Association 2013). Although the ability to form a fear memory is necessary for longterm survival and danger avoidance (Boissy 2004), individuals with PTSD exhibit maladaptive and overly robust fear memories that can be debilitating (Milad et al. 2008).

A history of chronic stress is a risk factor for the development of PTSD in humans (Breslau et al. 1999; Sareen 2014) and can create a PTSD-like phenotype in rodent models when chronic stress is paired with an aversive event (Daskalakis et al. 2013). The behavior of chronically stressed rats, as it pertains to fear conditioning, parallels observations from PTSD patients, including robust fear memories (Conrad et al. 1999; Cordero et al. 2003; Yehuda and LeDoux 2007; American Psychiatric Association 2013; Hoffman et al. 2015), generalization of fear responses to safe environments (Radulovic et al. 1998; Blechert et al. 2007; Hoffman et al. 2014), and resistance to extinction-based therapies (Blechert et al. 2007; Milad et al. 2009) or extinction training (Rau et al. 2005; Izquierdo et al. 2006; Miracle et al. 2006; Baran et al. 2009; Hoffman et al. 2014). Consequently, chronically stressed rodents tested on fear conditioning paradigms may provide unique insights into the neurobiology of PTSD (Bryant et al. 2008).

A feature of cognitive outcomes following chronic stress is that the passage of time can modulate the influence of chronic stress on certain cognitive processes. For example, when behavioral

\section{Corresponding author: conradc@asu.edu}

Article is online at http://www.learnmem.org/cgi/doi/10.1101//m.051060. 119. testing occurs within days after chronic stress has ended, spatial memory is compromised (Luine et al. 1994; Ghiglieri et al. 1997; Bowman et al. 2002; Abidin et al. 2004; Kleen et al. 2006; Song et al. 2006; Ortiz et al. 2015). However, when chronic stress ends and a rest period ensues, spatial abilities rebound and may even improve above and beyond those of their nonstressed counterparts (Luine et al. 1994; Hoffman et al. 2011; Bian et al. 2012; Ortiz et al. 2015; Conrad et al. 2017). In contrast, chronic stress leads to elevated anxiety (D'Aquila et al. 1994; Vyas et al. 2004; Huynh et al. 2011; Chiba et al. 2012; Eiland and McEwen 2012), which is often maintained weeks after the termination of chronic or acute stress (van Dijken et al. 1992; Adamec and Shallow 1993; Vyas et al. 2004). Consequently, time elapsed from the last stressor may differentially influence a range of cognitive and emotional processes.

Stressful events that might precipitate PTSD typically produce symptomology long after the stressful experience has ended (Schnurr et al. 2004; Xue et al. 2015). Consequently, investigating fear memories at time points further removed from the stressful event may be clinically relevant. Studies that have investigated a delay between the cessation of a stressor and the commencement of fear conditioning, using a single prolonged stressor or a chronic variable stressor a week before fear conditioning and extinction testing commenced, showed that rodents resisted fear extinction (McGuire et al. 2010; Knox et al. 2012). Whether this resistance to fear extinction persists weeks after the stressor has ended is unknown, but important to understand, considering the potential improvements that occur for spatial ability when 3 or 4 wk elapses

(C) 2020 Judd et al. This article is distributed exclusively by Cold Spring Harbor Laboratory Press for the first 12 months after the full-issue publication date (see http://learnmem.cshlp.org/site/misc/terms.xhtml). After 12 months, it is available under a Creative Commons License (Attribution-NonCommercial 4.0 International), as described at http://creativecommons.org/licenses/by-nc/4.0/. 
after chronic stress has ended (Sousa et al. 2000; Hoffman et al. 2011; Bian et al. 2012; Ortiz et al. 2015; Conrad et al. 2017). Consequently, the present study compared rats that had been recently chronically stressed with those that were remotely stressed 3 or 6 wk prior to fear conditioning (termed "stress-rest"), to determine whether the longer gap between the end of chronic stress and the start of fear conditioning was an important factor in the maintenance of robust fear memories.

\section{Results}

\section{Experiment 1: do rats resist fear extinction} 3 or $6 \mathrm{wk}$ after chronic stress ends?

Summary. All rats were fear conditioned (Supplemental Fig. 1) to three tone-footshock pairings in training Context A and then extinguished to the tone (30 trials, 15 trials/ day) in the nonshock Context $\mathrm{B}$ over the next $2 \mathrm{~d}$ (Fig. 1A). On the first three trials of Extinction Day 1, chronically stressed rats given a poststress rest period (chronically stressed-rest for three weeks (STR-R3), chronically stressed-rest for six weeks (STR-R6)) froze less to Context B than did CON and chronically stressedimmediate (STR-IMM), but all groups froze similarly to tone, which suggested a generalization of fear to context by CON and STR-IMM. Consequently, a difference score was calculated to determine how much freezing to tone occurred relative to the nonshock Context B; STR-R3 and STR-R6 discriminated between tone and context better than did CON and STR-IMM.

Specific results. During fear conditioning, freezing to tone increased in all groups (mixed factors analysis of variance (ANOVA) for group (CON, STR-IMM, STR-R3, STR-R6) across trials $(1,2,3)$ for tone, $\left.F_{(2,66)}=313.994, \quad P<0.001\right)$ with more freezing to tone as trials progressed $(P<0.05)$. Importantly, all groups froze similarly to tone during the third and last conditioning trial (one-way ANOVA for group, $F_{(3,36)}=0.834, \quad P=0.485$, Supplemental Fig. 1). Over the course of the $2 \mathrm{~d}$ of extinction, freezing to tone decreased and was nearly extinguished by the last trial (Fig. 1B, mixed factor ANOVA for group (CON, STR-IMM, STR-R3, STR-R6) by bins (3 trials/bin with 5 bins/day) revealed a significant effect of bin on Extinction Day $1\left(F_{(4,132)}=\right.$ $17.513, P<0.001)$ and Extinction Day 2 $\left(F_{(4,132)}=25.312, P<0.001\right)$ with no other significant effects). A week after extinction ended, spontaneous recovery was performed with three tone presentations in the nonshock context to determine whether the freezing was due to associative properties, which was confirmed. A return of freezing to tone was statistically similar across groups, although STR-R3 had a nonsignificant tendency toward less recovery than the other groups (Fig.
1C, one-way ANOVA for freezing to the first tone presentation). Freezing to tone ranged from $29.8 \pm 10.1 \%$ to $59.8 \pm 11.8 \%$.

The first three trials in Extinction Day 1 were investigated to understand the tone-shock memory prior to extensive extinction presentations; they revealed that groups performed similarly (Fig. 1D). A group (CON, STR-IMM, STR-R3, STR-R6) $\times$ trial $(1,2,3)$ ANOVA showed a significant effect of trial, $F_{(2,66)}=24.996, P<$ 0.001 , with no other significant effects. Freezing to tone increased from Trial 1 to Trial $2(P<0.001)$, and became statistically similar between Trials 2 and 3 . Importantly, all groups performed similarly. Freezing to Context B prior to the first tone ( $20 \mathrm{sec}$ prior to the first tone presentation, i.e., Baseline freezing to Context B) was assessed separately from subsequent context measures to determine whether any a priori differences existed before tone presentation. Freezing to context was similar for all groups (Fig. 1E, one-way ANOVA for freezing to Context $\mathrm{B}$, Baseline/Trial 1) and was

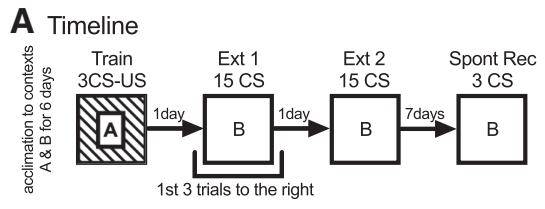

B Extinction Sessions by Bin: Freezing to Tone
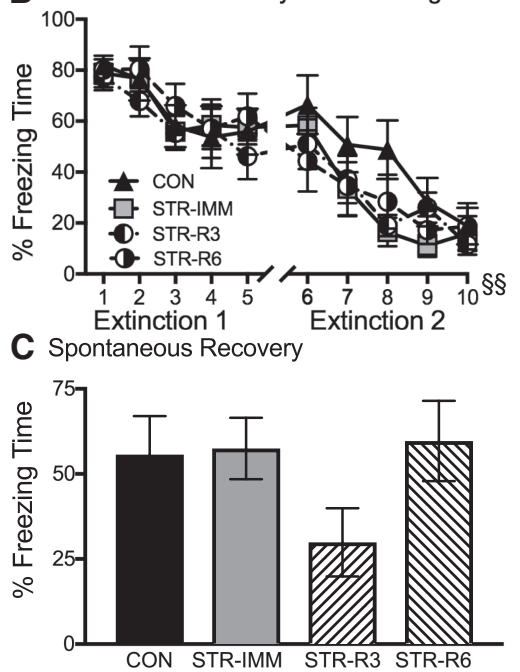

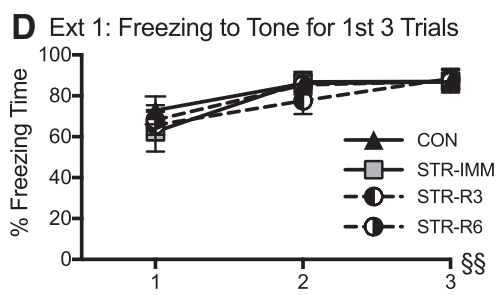

E Ext 1: Freezing to Context for 1 st 3 Trials

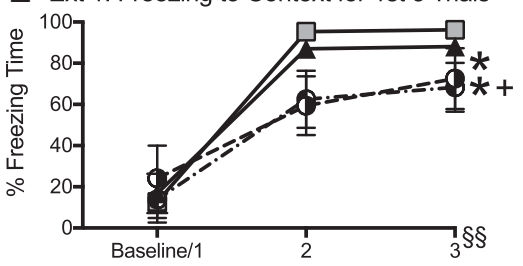

F Ext 1: Difference Score for 1st 3 Trials

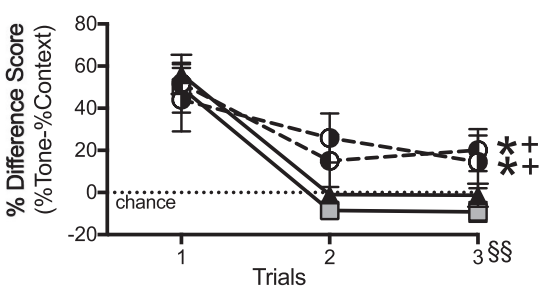

FIGURE 1. (A) Timeline of Experiment 1 . Rats were chronically stressed $(6 \mathrm{~h} / \mathrm{d} / 21 \mathrm{~d})$, which terminated 1,21 , or $42 \mathrm{~d}$ prior to the start of fear conditioning. Six days prior to fear conditioning, rats were acclimated to both contexts $(A, B)$ for 10 min daily, to reduce group differences in fear conditioning acquisition so that extinction processes could be studied (Hoffman et al. 2014). Fear conditioning occurred in Context A with 3 tone-footshock pairings. Groups performed similarly by the end of fear conditioning acquisition (data in Supplemental Fig. 1). Extinction to tone occurred in Context B on two subsequent days with spontaneous recovery occurring a week later. (B) Extinction to tone over Extinction Days 1 and 2. Freezing to tone decreased as trials progressed and groups performed similarly. Data are represented as bins of three trials. (C) Spontaneous recovery. One week after the last extinction session, all groups were returned to Context $B$ and presented with three tones. All groups showed a return of freezing to tone with no significant group differences. The timeline is illustrated in $A$. (D) Freezing to tone during the first three trials in Extinction 1. For the first tone presentation in Extinction 1 without footshock, all groups froze robustly to tone, and freezing to tone increased over the first three trials, with no group effects. $(E)$ Freezing to Context B during the first three trials in Extinction 1. While all groups showed very little freezing in Context B prior to the first tone presentation in Trial 1 (Baseline freezing level), differences became apparent during Trials 2 and 3: STR-R3 and STR-R6 froze less to context than did STR-IMM. Also, STR-R3 froze less to context than did CON, but did not reach significance for STR-R6. $(F)$ Difference score for the first three trials in Extinction 1. A difference score was calculated by subtracting freezing to Context B from freezing to tone to obtain a measure of selective fear memory to the cue. During Trials 2 and 3, STR-R3 and STR-R6 demonstrated higher difference scores than compared to both STR-IMM and CON. Moreover, STR-R3 and STR-R6 expressed difference scores that were above chance, showing selective freezing to tone than to Context $B$, whereas STR-IMM and CON froze at chance levels. Final number of subjects per group were $n=8-10$. (+) $P<0.05$ compared to CON, $\left(^{*}\right) P$ $<0.05$ compared to STR-IMM, $(\S \S) P<0.01$ across trials. 
relatively low, ranging from $12.7 \pm 10.0$ to $19.3 \pm 12.9 \%$. For subsequent Trials 2 and 3, rats given a rest after the end of chronic stress froze less to Context B than did STR-IMM or CON (mixed factor ANOVA for group (CON, STR-IMM, STR-R3, STR-R6) by trials $(2,3)$ showed significant effect of group $F_{(3,33)}=$ $3.991, P<0.05$, with no other significant effects). Specifically, STR-R3 froze significantly less to Context B than did STR-IMM $(P<0.05)$ or CON $(P<0.05)$ and STR-R6 froze significantly less to Context $B$ than did STR-IMM $(P<0.05)$ and froze less to Context B than did CON, but the difference was not statistically significant $(P=0.07)$. This suggests that, compared to STR-IMM and CON, both STR-R3 and STR-R6 froze less to a context that never involved footshock and hence, could be considered a "safe" context.

To understand how much freezing to the tone was due to associative processes over the more generalized freezing responses occurring in the absence of a discrete cue, a fear conditioning difference score was computed and analyzed. The difference score in Trial 1 was much higher $(P<0.001)$ than in Trials 2 and 3 (Fig. 1F, mixed factor ANOVA for group (CON, STR-IMM, STR-R3, STR-R6) by trial $(1,2,3)$ on the difference scores showed a significant effect of trial, $F_{(2,66)}=28.631, P$ $<0.001$, which was followed by a oneway ANOVA for the difference score in the first trial). The groups were statistically similar and showed high freezing to the tone over the context during Trial 1 (lowest difference score $=43.8 \pm 12.8 \%$, highest difference score $=53.9 \pm 8.6 \%$ ). This indicated low Baseline freezing to Context B in Trial 1. For Trials 2 and 3, however, a mixed factor ANOVA for group (CON, STR-IMM, STR-R3, STR-R6) by trial $(2,3)$ on the difference score, revealed a significant main effect of group, $F_{(3,33)}=5.557, P<0.05$, but no significant trial or interaction. Stress groups given a rest period after chronic stress, STR-R3 and STR-R6, froze selectively to tone over the nonshock Context B compared to STR-IMM $(P<0.05)$ and CON $(P<0.05)$, suggesting that STR-R3 and STR-R6 were better than STR-IMM and CON at learning that Context B was safe.

\section{Experiment 2: comparison of STR-IMM with STR-R6 on context generalization}

In Experiment 1, an extended acclimation paradigm was implemented to reduce contextual conditioning and, consequently, reduce generalization between contexts. However, the STR-IMM group, but not the STR-R3 or STR-R6 groups, froze similarly to the tone and the nonshock context, suggesting that STR-IMM had facilitated generalization of fear conditioning. Consequently, Experiment 2 was performed to test for differences in context generalization between STR-IMM and STR-R6.

As in Experiment 1, STR-IMM and STR-R6 were acclimated to Contexts $\mathrm{A}$ and $\mathrm{B}$ for $6 \mathrm{~d}$ and then underwent fear conditioning (3 tone/footshock trials; Supplemental Fig. 2). Half the rats were fear conditioned in Context A and the other in Context B (which were counterbalanced between groups). On the next day, rats were presented with three tones without footshock in Context B, which gave rise to rats being trained and then tested in different contexts $(\mathrm{A}+\mathrm{B})$ or in the same context $(\mathrm{B}+/ \mathrm{B})$, Figure $2 \mathrm{~A}$.

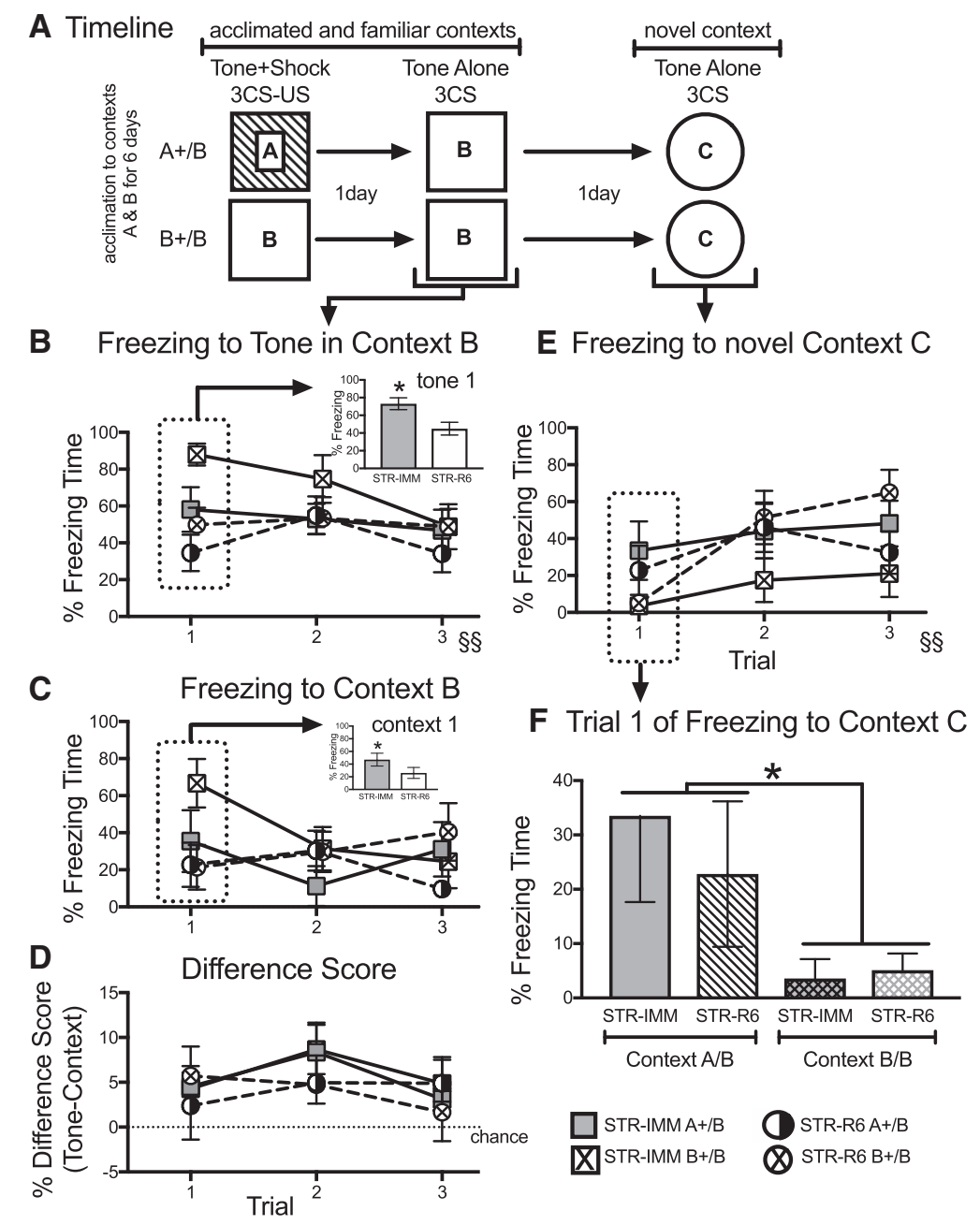

FIGURE 2. (A) Timeline of Experiment 2. Fear conditioning training consisted of 3 tone-footshock pairings in either Context $A$ or $B(A+$ and $B+$, respectively). The following day, rats were placed in Context $B$ and presented with three tones, giving rise to being tested in a different context from training $(A+/ B)$ or the same context as training $(B+/ B)$. No differences in freezing levels were found during acquisition of fear conditioning for either the stress condition (STR-IMM, STR-R6) or the contexts (data not shown). (B) Tone-alone presentation in Context B: freezing to tone. Differences among groups were observed in the first trial, with STR-IMM freezing more to tone than did STR-R6 (stress effect $\left({ }^{*}\right) P<0.05$ ), and groups trained and tested in the same Context $B(B+/ B)$ freezing more to tone than those trained and tested in a different context $(A+/ B)$ (context effect, $\left.\left(^{*}\right) P<0.05\right)$. (C) Tone-alone presentation in Context $B$ : freezing to context. Differences among groups were observed in the first trial (baseline freezing to Context B), with STR-IMM freezing more to Context B than did STR-R6 (stress effect, $\left({ }^{*}\right) P<0.05$ ). $(D)$ tone-alone presentation in Context $\mathrm{B}$ : difference score for freezing to tone minus freezing to Context B. Groups performed similarly with no significant differences. $(E)$ Tone-alone presentation in novel Context C: freezing to context. Freezing to novel Context " $\mathrm{C}$ " increased over trials for all groups, but rats trained and then tested in a different context $(\mathrm{A}+\mathrm{B})$ froze more to the novel context prior to any tone presentation (baseline freezing to novel Context $C$ ) than did rats trained and tested in the same context $(\mathrm{B}+/ \mathrm{B})$, which is illustrated in $F$. Freezing to tone in Context $\mathrm{C}$ was similar for all groups. Final number of subjects per group were $n=7-8$. For all graphs, $(\S \S) P<0.01$ for significant effect of trial. 
Whether trained and tested in a different $(\mathrm{A}+\mathrm{B})$ or in the same $(\mathrm{B}+/ \mathrm{B})$ context, STR-IMM froze more to tone and context in the first trial than did STR-R6 (Fig. 3B and 3B insert for tone, significant stress group by trial interaction, $F_{(2,50)}=5.304, P<0.05$, and significant trial effect, $F_{(2,50)}=5.304, P<0.05$; Fig. $2 \mathrm{C}$ and $2 \mathrm{C}$ insert for context, stress group on Trial 1 before tone presentation (baseline freezing to Context B), $\left.F_{(1,25)}=4.638, P<0.05\right)$. Also, freezing to tone decreased as trials progressed for all groups (Fig. 3B).

When the freezing to Context $\mathrm{B}$ was subtracted from the freezing to tone, no group differences were detected, and average difference scores were above chance levels (Fig. 2D). These data suggest that STR-IMM and STR-R6 discriminated between tone and context similarly, and that training context $(\mathrm{A}+/ \mathrm{B}$ or $\mathrm{B}+\mathrm{B})$ did not influence tone-context discrimination. Consequently, the high freezing to tone and to Context B by STR-IMM was indicative of a potentiated freezing response and not necessarily attributed to generalization.

On the next day, rats were placed into a novel context that was unfamiliar to them, in order to ascertain freezing in a nonacclimated, nonshock environment (see timeline in Fig. 2A). Rats were

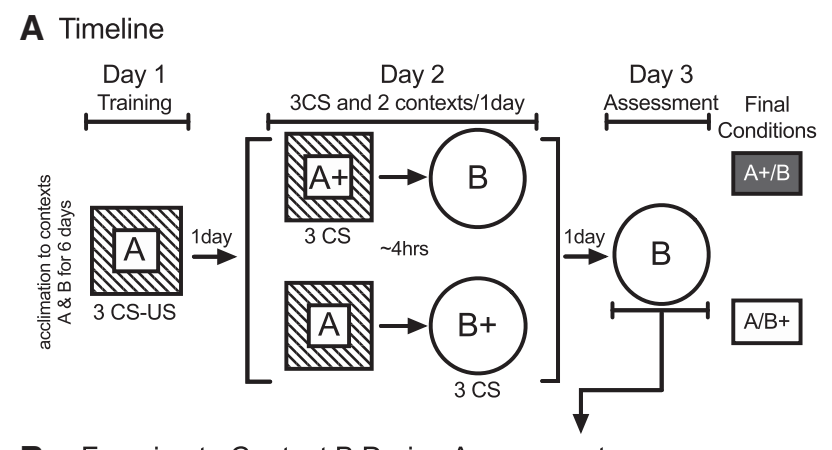

B Freezing to Context B During Assessment

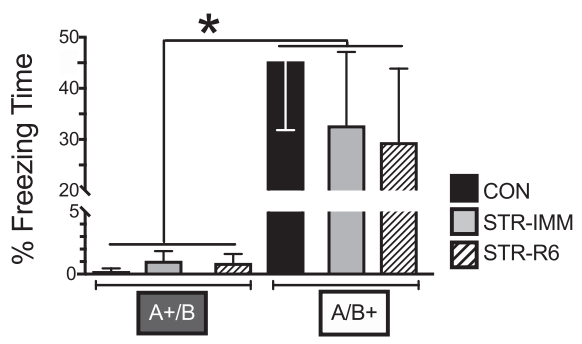

FIGURE 3. (A) Timeline of Experiment 3. Fear conditioning training consisted of 3 tone-footshock pairings in Context A. One day later, rats were returned to Context $A$, with half of them exposed to the tone again in this environment and the other half not exposed. Later that same day, all the rats were placed in the nonshock Context $B$; rats that did not receive tone presentations in Context $A$ were then exposed to three tones in Context $B$; those that received the tone presentations in Context $A$ did not receive tones during this time. This led to the two conditions, $A^{+} / B$ and $A / B^{+}$, respectively, based upon the context that had tone-alone presentations. Consequently, all groups received similar tone and context exposures leading into the assessment day. The following day, (Day 3) the amount of freezing to Context $B$ was assessed. (B) Freezing to Context B during assessment. If the rats formed second-order conditioning, then rats that received tone presentations a day earlier in Context $B(A / B+)$ would be expected to show higher freezing to Context $B$ during the assessment. As expected, all groups in the $A / B+$ condition froze more to Context $B$ than did the rats that never received a tone in Context B previously. There were, however, no other significant effects, indicating that second-order conditioning was similar for CON, STR-IMM, and STR-R6. Final number of subjects per group were $n=7-8$. $\left.{ }^{*}\right) P<0.001$ compared to A+/B. presented with the tone cue (no shock) three times. Whereas the groups showed similar freezing to the tone across the trials (data not shown), differences were observed in baseline freezing to Context C, prior to the first tone presentation (Fig. 2E). Specifically, rats trained and tested in the same training condition $(B+/ B)$, froze significantly less to the novel Context $C$ than did the rats who were trained and then tested in a different context $(A+/ B)$; stress history (STR-IMM, STR-R6) did not modify the outcome (Fig. $2 \mathrm{~F}$, significant training context, $\left.F_{(1,25)}=4.762, P<0.05\right)$. After the presentation of the tone, freezing to the novel Context $C$ increased and was similar across all groups and across the remaining two trials $\left(F_{(2,50)}=11.989, P<0.001\right)$, without any other significant main effects or interactions.

\section{Experiment 3: are STR-IMM showing second-order conditioning during extinction?}

Compared to STR-R6, STR-IMM showed heightened fear responses early in extinction in Experiment 1 and fear generalization was excluded as a possible interpretation in Experiment 2. Another possible explanation for the more robust fear responding in STR-IMM is that they more readily formed a strong second-order tone-context association, which is most likely to happen when the original toneshock association is strong. Indeed, individuals with PTSD are more likely to form second-order associations between traumarelated and neutral cues (Wessa and Flor 2007). In Experiment 3, we tested for second-order conditioning with context as the second-order cue (Fig. 3A).

On Day 1, rats (CON, STR-IMM, STR-R6) underwent fear conditioning (first-order) as described in Experiment 1 (Supplemental Fig. 3A,B). On the next day, rats were returned back to Context A, the environment where they had been exposed to tone and footshock. Half the rats were presented with three tones and the other half exposed to Context A without tones. Approximately $4 \mathrm{~h}$ later, the rats were brought to Context $\mathrm{B}$, which was used as the second order cue. The rats exposed to Context A earlier without tone presentations were now presented with three tones in Context $B$, while the remainder who received tones earlier in Context A were placed in Context B without the tone presentations. Therefore, all rats had equal exposure to both contexts and tones, but with different pairings of tone and environment: rats that received tone only presentations on Day 2 in the same context as training were designated as $A+/ B$ and those that received the second-order conditioning paradigm on Day 2 with tone in Context $\mathrm{B}$ were designated as $\mathrm{A} / \mathrm{B}+$. Rats in the $\mathrm{A} / \mathrm{B}+$ showed similar and high freezing to Context $B$ by the end of the second-order conditioning session (one-way ANOVA for freezing to Context Trial 3, $F_{(2,21)}=0.668, P=0.524$; Supplemental Fig. $\left.3 \mathrm{C}\right)$. On the third day, rats were returned to Context $\mathrm{B}$ to assess their potential for second order conditioning.

When freezing to Context $\mathrm{B}$ was assessed for second-order conditioning on Day 3, groups trained in the $\mathrm{A} / \mathrm{B}^{+}$order showed more freezing to Context $B$ than did rats trained in the $A^{+} / B$ order, but stress history did not modify performance (Fig. 3B, mixed factors ANOVA for group (CON, STR-IMM, STR-R6) by training history $(\mathrm{A} / \mathrm{B}+, \mathrm{A}+\mathrm{B})$ for freezing to Context $\mathrm{B}$ showed a significant effect of training history, $F_{(1,44)}=24.536, P<0.001$, with no other significant effects).

\section{Discussion}

The goal of this study was to investigate whether chronically stressed rats provided with a poststress rest period would show facilitated fear extinction learning compared to chronically stressed rats without a rest period. We used an extended acclimation model (6 d) to the training and testing contexts because it leads to similar 
fear conditioning acquisition across groups (Hoffman et al. 2015). Consequently, differences in learning were minimized, allowing us to focus on extinction processes. During the early extinction trials in Experiment 1, the two chronically stressed groups given a poststress rest period (STR-R3 and STR-R6) displayed lower freezing to the nonshock context than did nonstressed rats or recently chronically stressed rats. When the amount of freezing to the context was subtracted from the amount of freezing to the tone, both groups of chronically stressed rats with a poststress rest period consistently demonstrated positive and high difference scores early in extinction during Day 1 compared to nonstressed rats or recently chronically stressed rats. This reveals that early in extinction, both groups of chronically stressed rats with a poststress rest period were better able to discriminate the tone from the context by freezing less to the context that never included a footshock than did nonstressed rats or recently chronically stressed rats. As trials progressed, all groups showed similar extinction rates later on Day 1 and throughout Day 2.

Interestingly, the recently chronically stressed group appeared to freeze similarly and robustly to tone and context during the first few trials of extinction, suggesting a generalization of fear across contexts. Consequently, Experiment 2 was performed to assess potential context generalization by testing recently chronically stressed rats in an environment that differed $(\mathrm{A}+\mathrm{B})$ or was the same as $(\mathrm{B}+/ \mathrm{B})$ the conditioning environment, using chronically stressed rats with a $6 \mathrm{wk}$ rest period (STR-R6) as a comparison. The results revealed that recently chronically stressed rats discriminated between tone and context, but showed higher freezing to both tone and contexts (regardless of whether or not the context was associated with a priori exposure to footshocks) than did chronically stressed rats with a rest period. Taken together, the recently chronically stressed group may be exhibiting higher freezing, reflecting hypervigilance, but not necessarily higher freezing due to generalization under this extended acclimation paradigm.

Another interesting finding from Experiment 2 was that when placed into a completely novel context (Context C), rats in the A/B training froze more than rats that were in the $\mathrm{B} / \mathrm{B}$ training, an outcome that was unaffected by stress history. While tone presentation in a novel context may evoke similarities to a renewal paradigm, there were important distinctions. In renewal, a previously extinguished conditioned response is evoked following the conditioned stimulus presentation in a novel context (Bouton 2004). However, rats in Experiment 2 were given just 3 tone-only presentations on the previous day, which was insufficient to extinguish the conditioned response. Moreover, groups in our study differed in their freezing responses to the novel context even before the tone (or the conditioned stimulus that is integral to renewal) was presented. Consequently, renewal fails to explain the high freezing to Context $\mathrm{C}$ by rats in the $\mathrm{A} / \mathrm{B}$ group versus rats in the $\mathrm{B} / \mathrm{B}$ group. Instead, training history likely impacted the perception of a novel environment. Specifically, the A/B group was exposed to the conditioned tone in more than one context (A and $\mathrm{B}$ ) and perhaps they anticipated that environments could signal danger, including a novel environment. In contrast, the $\mathrm{B} / \mathrm{B}$ group experienced the conditioned tone in only one context and perhaps they were less likely to generalize their fear. Although the goal of Experiment 2 was to test for generalization, which was not explicitly observed (Test in Context B), the higher freezing to novel Context $\mathrm{C}$ by rats in the $\mathrm{A} / \mathrm{B}$ group supports that a relationship exists between testing experience and novel contexts. Having experienced a conditioned cue associated with danger in at least two contexts may lead to the generalization of danger to novel contexts. This finding could relate back to how PTSD forms with danger-related cues that are paired with otherwise safe environments (Rizley and Rescorla 1972; Grillon et al. 1998; Gewirtz and Davis 2000; Rothbaum and Davis 2003; Jovanovic et al. 2012).
Another possible explanation for the heightened freezing to context in the nonshock context in Experiment 1 was that recently chronically stressed rats readily formed second-order associations with fear-related cues. Specifically, we hypothesized that the previously conditioned cue (tone), would be associated with the context in which it is presented, such that the context would then be indirectly associated with the aversive event (Rizley and Rescorla 1972; Gewirtz and Davis 2000). Indeed, results from human studies suggests that second-order conditioning in a safe context contributes to the maintenance of responding to traumarelated cues (Wessa and Flor 2007). In Experiment 3, we demonstrated that, when presented with the tone (the first-order conditioning stimulus) in a nonshock environment, the nonshock environment functions as a second-order conditioning cue for recently chronically stressed rats. However, recently chronically stressed rats, chronically stressed rats with a 6 wk rest period, and nonstressed rats all performed similarly. Our results did not support the idea that second-order conditioning contributed to the more robust freezing responses in recently chronically stressed rats. We suspect that instead of solely achieving second-order conditioning, we might have also encountered some other compoundstimuli phenomena, such as latent inhibition (discussed next, see also (Rauhut et al. 1999; Brembs and Heisenberg 2001; Urcelay and Miller 2009).

Latent inhibition is a phenomenon in which a neutral cue is paired with a meaningful stimulus, leading to two competing interpretations, neutral or meaningful. As it pertains to the current study, rats received extensive nonreinforced exposure to the nonshock Context B during acclimation, and so Context B likely had a "neutral" or "safe" meaning (see Fig. 1E, Baseline, low freezing to Context B prior to the introduction of the first tone). Consequently, when the shock-paired tone was introduced to Context $\mathrm{B}$, the rat freezing response to Context $\mathrm{B}$ may have reflected a combination of information: the previous information that Context $\mathrm{B}$ was neutral and the new information coming from a predictive tone. In this view, freezing during Trials 2 and 3 of Extinction may have reflected the combination of an inhibitory response to Context $\mathrm{B}$ and an excitatory response to the tone, a test of which would be similar to a summation test for latent inhibition (Rescorla 1969; Foilb et al. 2018). While we did not explicitly test for latent inhibition, it is possible that the strength of latent inhibition was enhanced in chronically stressed rats provided with a rest period. Future studies should investigate the degree to which latent inhibition is able to control behavior in chronically stressed rodent models, as this has important clinical implications for patients with PTSD (Grillon et al. 1998; Jovanovic et al. 2012).

A defining feature of PTSD is a failure to recognize or appropriately respond to safety signals, cues that should indicate safety even in the presence of a trauma related cue (Grillon et al. 1998; Jovanovic et al. 2012). Extinction training, which here consisted of the shock-paired tone presented in a nonshock environment, should lead to a suppression of the fear response to the tone because of the new association that the tone in this environment does not predict shock. As such, the nonshock environment becomes a safety signal for when shock will not occur (Rothbaum and Davis 2003). In the present study, we found that recently chronically stressed rats froze to the "safe" context in extinction more than chronically stressed rats with a rest period of 3 or 6 wk, as seen in the first three trials of extinction in Experiment 1 and during the first context of Test 1 in Experiment 2. Perhaps the recently chronically stressed group had difficulty in identifying the safety signals as quickly as the chronically stressed rats with a rest period cohorts. A similar argument would suggest that chronically stressed rats with a rest period were better able to learn safety signals because of their lower freezing levels during extinction sessions. Future work should continue to investigate the behavioral 
mechanisms that lead to better, more flexible outcomes in the aftermath following chronic stress.

Taken together, the freezing responses to tone reflected associative learning in the present study. In Experiment 1, all groups showed spontaneous recovery seven days after the last extinction session, with freezing to tone ranging from $32.4 \pm 9.8 \%$ to $52.7 \pm$ $10.7 \%$ in the first two trials. Moreover, groups showed statistically similar freezing to the tone during spontaneous recovery. The return of freezing response in chronically stressed rats with a $3 \mathrm{wk}$ rest period showed a tendency to be less robust than the other groups, but this was unlikely to be attributed to a priori differences, as all groups showed similar and low levels of freezing by the end of Extinction 2. Consequently, the freezing to tone during the spontaneous recovery session likely reflected associative processes, as opposed to carry-over effects from extinction or nonassociative effects (Ji and Maren 2007). Additional supporting evidence was that, in Experiment 1, the freezing response was nearly absent in all groups prior to the first tone presentation in extinction using a nonshock context (i.e., Baseline freezing), in which footshock would be least expected. After the tone was presented in the nonshock context, freezing subsequently increased and this phenomenon was replicated in Experiment 2 with the two different contexts. Hence, this evidence suggests that freezing to tone reflected an association formed between tone and footshock during conditioning.

In the present studies, most key findings arose from freezing to the context or the difference score that incorporated freezing to context, rather than from freezing to the tone cue. In Experiment 1 specifically, the introduction of the tone to the extinction context led to enhanced freezing to context in all groups, as well as significant group differences in freezing to context (Fig. $1 \mathrm{E}$, trials 2 and 3 ). However, a potential concern is that freezing to tone may have contributed to the freezing to context directly (e.g., carry-over from prior tone presentation) or indirectly (e.g., through a context-tone association activated by tone presentation). Nonetheless, by incorporating a measure of freezing to tone, the difference score partially addresses these concerns. In particular, if significant effects on freezing to context were merely due to differences in freezing to tone that spilled over to the context through carry-over, higher-order associations, generalization, or any other mechanism, then these spill-over effects could be eliminated by subtracting freezing to tone from freezing to context (or context from tone, as was conducted here). However, if treatment selectively affected the magnitude of such tone-to-context spillover without significantly affecting freezing to tone itself, then significant treatment effects on difference scores may still arise. As unlikely as the latter possibility might be, it cannot yet be ruled out.

This study is one of the first to investigate fear extinction processes based upon the timing from the end of chronic stress. In a prior study, rats given a single prolonged stressor and then tested for fear conditioning and extinction seven days later show poor retention of fear extinction (Knox et al. 2012). Another report used chronic variable stress and then tested rats on fear conditioning and extinction seven days later and found resistance to fear extinction (McGuire et al. 2010). The present study adds to this literature and revealed that chronically stressed rats given a 3 or 6 wk rest period after chronic stress ended, show fear extinction that differs from either controls or stressed rats tested soon thereafter. Our results support the interpretation that exposure to a traumatic event 3 or 6 wk after a chronic stress history leads to a different fear extinction profile than had a traumatic event occurred soon after chronic stress ended.

A possible interpretation for the chronically stressed rats with a rest period improved discrimination of the conditioned tone from context is an inoculation effect. For example, stressor exposure early in life can lead to less anxiety and better cognitive flexi- bility when faced with stressors later in life (Katz et al. 2009; Lyons et al. 2009, 2010). In the present study, when young adult rats were chronically stressed, they demonstrated better discrimination between a conditioned cue and the safe context when they were permitted 3 or 6 wk of rest following the end of chronic stress, compared to rats tested soon after stress ended. A similar finding has been observed for spatial memory in that a rest period following the end of chronic stress leads to better performance compared to a delay of a few days (Hoffman et al. 2011). This suggests that, under some circumstances, an earlier chronic stress experience can be helpful in navigating a later stressful experience.

A significant amount of PTSD patients do not seek therapy until much later after the traumatic event, giving the traumatic memory a chance to strengthen (Bryant 2017b). Indeed, symptoms must be present for at least one month before PTSD can be diagnosed (American Psychiatric Association 2013). In the present study, however, extinction training occurred in the days after fear conditioning (i.e., the traumatic experience). This was performed because it allowed for early assessment, as some patients exhibit PTSD-associated symptoms immediately after a traumatic event, called acute stress disorder, or ASD (American Psychiatric Association 2013). If left untreated, ASD could become PTSD (Bryant 2017a). Our current study suggests that it is possible that early extinction therapies in individuals showing ASD symptoms might lead to reduced PTSD rates. This is supported by the observation that the recently chronically stressed group was able to eventually extinguish their elevated freezing to the cue tone and context to a similar level as the other groups as extinction continued. Further supporting evidence is that recently chronically stressed performed similarly to the rest of the conditions during the measurement of spontaneous recovery. Future studies should investigate fear responding to extinction in weeks after fear conditioning to determine whether early extinction therapies could inoculate against PTSD.

The results of the present study suggest that when contexts are familiar, such as with our paradigm that included an extensive acclimation prior to training, chronically stressed individuals perform differently during the initial fear extinction acquisition process, depending upon whether extinction occurs soon after chronic stress ends or after a rest period. Chronically stressed individuals soon thereafter exposed to fear extinction discriminated between the conditioned stimulus and safe environment, but exhibited high freezing, perhaps due to being hypervigilant. Follow-up studies ruled out the possibility that chronically stressed subjects were generalizing or forming a stronger second-order context-tone association than the other groups. When chronically stressed individuals were exposed to fear extinction after a 3 or $6 \mathrm{wk}$ rest period, they also discriminated between the conditioned stimulus and safe environment, but without showing hypervigilance. Typically, clinical populations with PTSD show heightened responses to trauma related cues and impaired improvement with extinction-based therapies. In the present study, the stress group that best modeled these PTSD-like characteristics was the recently chronically stressed group, which displayed more freezing to context during extinction training than either the chronically stressed with a rest period groups. This suggests that the time between chronic stress and the trauma exposure is a factor that may influence PTSD development.

\section{Materials and Methods}

\section{Subjects}

Male Sprague-Dawley (Charles River Laboratories) rats weighing $\sim 250$ g upon arrival were pair housed in standard laboratory cages $\left(21^{\circ} \mathrm{C}-22^{\circ} \mathrm{C}\right.$, corncob bedding). Except where noted below, 
animals were allowed food and water ad libitum. Animals were housed on a reverse 12:12 light cycle, with lights off at 7 a.m. All procedures occurred during the dark phase of the light cycle and were performed in accordance with the Guide for the Care and Use of Laboratory Animals and the approval of the Arizona State University Institutional Animal Care and Use Committee.

\section{Chronic stress procedure}

Rats were chronically stressed by restraint for $6 \mathrm{~h} / \mathrm{d}$ for $21 \mathrm{~d}$. Our previous work demonstrated that these restraint parameters were the minimum required duration for restraint stress to produce behavioral and structural changes (McLaughlin et al. 2007). Restraint took place between 9 a.m. and 3 p.m. and occurred in the animal's home cage. Sound-attenuating chambers kept the animals undergoing restraint separated from animals not undergoing restraint. To keep food and water access similar between groups, the control group was yoked to the stress groups and their food and water was removed during restraint hours. Additionally, control rats were handled at the start of each day to keep daily handling by the investigator consistent. Animals were initially restrained using a wire mesh tube $(6.4 \mathrm{~cm}$ DIA $\times 26.7 \mathrm{~cm} \mathrm{~L})$ that was made using grip guard sealer (Flynn and Enslow) to keep the wire ends coated, but were upgraded to a larger restrainer $(7.6 \mathrm{~cm}$ DIA $\times 29.2 \mathrm{~cm} \mathrm{~L})$ as the rats grew. Weights were recorded weekly to confirm stressor effectiveness.

\section{Group assignments and timeline}

In Experiment 1, rats were assigned to one of four groups $(n=10$ / group, 40 rats total): control (CON), chronic stress with a $6 \mathrm{wk}$ rest period (STR-R6), chronic stress with a 3 wk rest period (STR-R3), or chronic stress without a rest (i.e., tested within days or immediately, STR-IMM). Training on fear conditioning occurred $6 \mathrm{wk}$ (STR-R6), $3 \mathrm{wk}$ (STR-R3), or within days (STR-IMM) from the last day of restraint. The 3 and 6 wk rest durations were selected because some behaviors, such as spatial ability, improve $3 \mathrm{wk}$ after chronic stress has ended (Luine et al. 1994; Hoffman et al. 2011; Bian et al. 2012; Ortiz et al. 2015; Conrad et al. 2017), although anxiety may stay elevated (Mikics et al. 2008). For Experiment 2, two stress groups were used, STR-IMM or STR-R6, and rats were further classified based on their conditioning environment for a total of four groups ( $n=8$ /group, 36 rats total). In Experiment 3, three stress groups were used, CON, STR-IMM, and STR-R6, and rats were further classified based on whether they underwent second-order conditioning or not for a total of six groups ( $n=8$ /group, 48 rats total).

\section{Fear conditioning}

Fear conditioning apparatus. Rat test cages were square and made of metal and plastic $(30.5 \mathrm{~cm} \mathrm{~W} \times 25.4 \mathrm{~cm} \mathrm{D} \times 30.5 \mathrm{~cm} \mathrm{H}$ : Coulbourn Instruments, E10-18TC or H10-11R-TC) and were modified so that the top metal panel was replaced with clear Plexiglas for video recording. Both arenas were housed within a purchased sound-attenuating cabinet (Coulbourn, E10-23, white, $78.7 \mathrm{~cm}$ $\mathrm{W} \times 53.3 \mathrm{~cm} \mathrm{D} \times 50.8 \mathrm{~cm} \mathrm{H}$ ) or a custom-made sound-attenuating cabinet $(63.5 \mathrm{~cm} \mathrm{~W} \times 61.0 \mathrm{~cm} \mathrm{D} \times 71.1 \mathrm{~cm} \mathrm{H}$ : Melamine boards). Tones ( $75 \mathrm{~dB}$ steady tone, $20 \mathrm{sec}$ ) were delivered through a speaker (Coulbourn, H12-01R) mounted on the inside of the sound-attenuating cabinet and were produced by a frequency generator (Coulbourn, E12-01 or H12-07). An animal shock generator (Coulbourn, H13-15) administered the shocks (0.8 mA, $1 \mathrm{sec})$ through a shock floor (Coulbourn, E10-18RF or H10-11RTC-NSF), with current equally distributed between parallel metal bars. Illumination was provided throughout testing by LED light bulbs in porcelain lamp-holders (Pass \& Seymour, Legrand) mounted to the ceiling of the isolation cubicles.

All stimuli were controlled using Graphic State software (v 4.0 GS4-UP). Graphic State was installed on a Dell computer $(3.19 \mathrm{GHz}$, Intel i5 CPU, 64 bit) running Windows 7 Enterprise (2009, Microsoft Corp.). The computer was connected to a linc system (Coulbourn, H02-08) that controlled the stimuli output via an USB interface (Coulbourn, U90-11H). Infrared lights (Coulbourn,
H27-91R) were positioned to be observed by the video and were programed to denote the context and tone. The infrared lights could not be visually detected unless viewed on video.

Behavioral quantification. All behavior was digitally recorded on GoPro Hero 3 cameras (GoPro, Inc.) for offline analysis. Video from the GoPro cameras were monitored using a Quad Splitter Processor (Evertech), which allowed four videos to be viewed on one monitor (Samsung, 24"). The behavior from eight single chambers that were viewed on two monitors was also backed up on a VCR/DVD recorder (Funai). Behavior was manually scored by a trained observer. Freezing was defined as the lack of all movement, except those associated with respiration (Blanchard and Blanchard 1969). Freezing to tone was defined as any freezing that took place during the $20 \mathrm{sec}$ tone presentation and freezing to context was defined as any freezing that took place in the 20 sec immediately prior to the presentation of the tone. A fear conditioning difference score was calculated in order to assist in understanding how much of the freezing to the tone was due to associative processes over a more generalized, nonassociative freezing response that may occur in the absence of the discrete cue. This was calculated as the amount of freezing to tone minus the amount of freezing to context $20 \mathrm{sec}$ prior to the tone (similar to Majchrzak et al. 2006). Inter-rater reliability was $97.3 \pm 6.4 \%$ and intra-rater reliability was $95.7 \pm 2.0 \%$.

Environments for fear conditioning procedures. Over the course of the three experiments, three different contexts were used. In one context, the testing cages were square metal and plastic and had a metal floor of parallel rods (Coulbourn, H10-11RTC-SF), silver side panels (Coulbourn, H90-00R-M-KT01), and black and white striped panels on the clear plastic back wall. The sound-attenuating cabinet contained a 40-Watt equivalent LED bulb (450 Lumens; Osram Sylvania, Inc.) and a white-lit LED computer fan (Thermaltake, CL-F020-PL12WT-A or Coulbourn, ACT-130). The cleaning solution used after each rat was an allpurpose, grapefruit scented cleaner (Method, Inc.) and the room lighting of the overall holding room was white light. Experimenters wore a yellow wrap gown and black gloves. Rats were transported from the colony room to the testing room by hand-carrying the rats in their home cages. For a second context, the testing cages were round, plastic blue buckets $(37 \mathrm{~cm} \mathrm{H} \times 30.5 \mathrm{~cm}$ DIA, Lowes). A 3-Watt, Red LED bulb (91 Lumens; Feit Electric) was used as illumination in the isolation cubical. A $35.6 \mathrm{~cm}$, computer fan with red LED light (Thermaltake, TT-1425) provided white noise/ventilation in the cubicle. The cleaning solution used after each rat was $70 \%$ isopropyl alcohol (Vi-Jon, Inc.). Experimenters wore a white lab coat and blue gloves. The rats were transported from the colony room to the testing room in their home cages on a cart and the room lighting of the overall holding room was red light. For the third context, the testing cages were modifications of the square testing cages (Coulbourn, H10-11R-TC-SF). A black semi-circular Plexiglas insert was placed in the testing cage to produce a curve in the back. The exposed side panels were covered in black plastic. Room lighting, transportation method, isolation cubical door positioning, chamber lighting, and computer fan used were the same as in the second context. The cleaning solution used after each rat was an all-purpose pine scented cleaner (Method, Inc.).

\section{Experimental procedures}

Experiment 1: influence of a rest period following the end of chronic stress on fear extinction. Six days before the chronic restraint procedure ended for the last cohort of rats (STR-IMM), acclimation to the contextual environments commenced. The goal of the acclimation sessions was to reduce conditioning to the environments and decrease possibilities for generalization between the contexts allowing extinction processes to be studied without a priori differences in baseline freezing (Jacobs et al. 2010; Hoffman et al. 2014, 2015). Acclimation occurred $\sim 1 \mathrm{~h}$ after restraint ended each day so they would have ample opportunity to access food and water prior to acclimation sessions. Rats were acclimated by being placed in a context for $10 \mathrm{~min}$ daily. Exposure to the two contexts alternated over the $6 \mathrm{~d}$ for a total of three exposures to each context. The day after the last acclimation session 
(Day 7), fear conditioning training occurred in Context "A." Training consisted of three tone-footshock pairings (intertrial interval (ITI) range between pairings $=80-170 \mathrm{sec}$ ), with the first tone was presented after $114 \mathrm{sec}$. The training session lasted 535 sec. One and two days after training, rats underwent extinction training sessions in Context "B." Extinction training consisted of 15 presentations of the tone (ITI range $=85-120 \mathrm{sec}$ ). Seven days after the second extinction session, rats were exposed to three more presentations of the tone in Context $\mathrm{B}$ to assess spontaneous recovery (ITI range $=90-120 \mathrm{sec}$ ).

Experiment 2: comparison of STR-IMM with STR-R6 on context generalization. In Experiment 1, there were indications that STR-IMM might be generalizing their fear responses to the nonshock environment, so a second experiment to test for generalization was performed. STR-R6 was used as a comparison group due to low freezing to context seen in this group, and because a goal of Experiment 2 was to better understand the differences between the chronic stress groups. A nonstressed group was not included here because the comparison in generalization between CON and STR-IMM has been previously reported (Hoffman et al. 2014). Acclimation and fear conditioning occurred as described in Experiment 1, whereby rats were acclimated to both environments over $6 \mathrm{~d}$ and then fear conditioned (three tone and footshock pairings) the following day in either Context " $A$ " or " $B$," which were counter-balanced across groups. A day after fear conditioning, all rats were given three tone-alone presentations in Context B (ITI $=320 \mathrm{sec})$. One day later, the rats were placed in a novel Context " $\mathrm{C}$," where they had no prior acclimation experience and then presented with three tone alone presentations.

Experiment 3: investigation as to whether STR-IMM is more likely to form second-order conditioning than CON or STR-R6. This experiment was done to test whether STR-IMM were more likely to form a second-order association between the tone and the extinction context compared to STR-R6 or CON. Acclimation occurred over $6 \mathrm{~d}$ as described in Experiment 1. One day after acclimation ended, fear conditioning occurred in Context "A." Training consisted of three tone-footshock pairings as in Experiment 1 . One day after training, all the rats were reexposed to Context $\mathrm{A}$ in the morning, with half of them receiving threetone presentations $\left(\mathrm{A}^{+} / \mathrm{B}\right)$. In the afternoon, all rats were exposed to Context "B," with the half that did not get exposed to the tone in the morning receiving three-tone presentations $\left(\mathrm{A} / \mathrm{B}^{+}\right)$for the second-order conditioning manipulation. This led to a $3 \times 2$ design for stress group (CON, STR-IMM, STR-R6) and second-order conditioning or not $(\mathrm{A} / \mathrm{B}+, \mathrm{A}+\mathrm{B})$. The following day, all groups were tested for contextual freezing behavior in Context $\mathrm{B}$.

\section{Statistical analysis}

Results were analyzed using ANOVA. Results that were significant at the $P<0.05$ level were additionally analyzed using the LSD (least significant difference) post-hoc test. Rats were excluded from further analysis if freezing to context exceeded $25 \%$ of the total freezing prior to the first presentation of tone during training (i.e., before tone or footshock presentation). Three rats were excluded from both Experiment 1 (1 CON, 2 STR-IMM) and Experiment 2 (1 STR-R6 B+/B, 1 STR-IMM A+/B, 1 STR-IMM B $+/ \mathrm{B})$. Please note that due to equipment malfunction, some data were lost in Experiment 3 to produce $n=7$ or 8/group $(n=7$ for STR-R6-A+/B for Training Day 2 a.m. and p.m. sessions, for STR-R6-A/B+ for Training Day 2 a.m. and Test Day, for STR-IMM-A+/B for Training Day 2 a.m. and p.m. sessions and Test Day, for STR-IMM-A/B+ for Training Day 2 a.m. and p.m. sessions, for CON-A+/B for Training Day 2 a.m. and p.m. sessions, and for CON-A/B+ for Training Day 2 a.m. session.) To correct for unequal variances, data was transformed using $\sqrt{x+1}$ (Fidell and Tabachnick 2007). Data analysis was done using SPSS Version 24 on an Apple iMac running macOS Sierra (v 10.12.6).

\section{Acknowledgments}

The authors gratefully acknowledge the contributions of Amanda Acuña, Bryce S. Badaruddin, Eshaan J. Daas, Megan E. Donnay,
Diego Padilla-Garcia, Aaron Flegenheimer, Elizabeth Hanson, Brittany Le, Logan Martin, Kenji J. Nishimura, Dylan N. Peay, Cindy Reynolds, Hovhannes Michael Saribekyan, Rujuta Takalkar and Gillian Thornton, Iva Vracar, and Christopher Willis. We are also especially appreciative to the Arizona State University Department of Animal Care and Technology for their exemplary care for the animals used in these experiments. This work was funded in part by The College, Liberal Arts and Sciences, and Knowledge Enterprise Development at Arizona State University (Conrad) and the Department of Psychology Enhancement Award at Arizona State University (Judd).

\section{References}

Abidin I, Yargiçoglu P, Agar A, Gümüslü S, Aydin S, Öztürk O, Sahin E. 2004 The effect of chronic restraint stress on spatial learning and memory: relation to oxidant stress. Int J Neurosci 114: 683-699. doi:10.1080/ 00207450490430543

Adamec RE, Shallow T. 1993. Lasting effects on rodent anxiety of a single exposure to a cat. Physiol Behav 54: 101-109. doi:10.1016/0031-9384 (93)90050-P

American Psychiatric Association. 2013. Diagnostic and Statistical Manual of Mental Disorders.

Baran SE, Armstrong CE, Niren DC, Hanna JJ, Conrad CD. 2009. Chronic stress and sex differences on the recall of fear conditioning and extinction. Neurobiol Learn Mem 91: 323-332. doi:10.1016/j.nlm.2008 .11 .005

Bian Y, Pan Z, Hou Z, Huang C, Li W, Zhao B. 2012. Learning, memory, and glial cell changes following recovery from chronic unpredictable stress. Brain Res Bull 88: 471-476. doi:10.1016/j.brainresbull.2012.04.008

Blanchard RJ, Blanchard DC. 1969. Crouching as an index of fear. J Comp Physiol Psychol 67: 370-375. doi:10.1037/h0026779

Blechert J, Michael T, Vriends N, Margraf J, Wilhelm FH. 2007. Fear conditioning in posttraumatic stress disorder: evidence for delayed extinction of autonomic, experiential, and behavioural responses. Behav Res Ther 45: 2019-2033. doi:10.1016/j.brat.2007.02.012

Boissy A. 2004. Fear and fearfulness in animals. Q Rev Biol 70: 165-191. doi:10.1086/418981

Bouton ME. 2004. Context and behavioral processes in extinction. Learn Mem 11: 485-494. doi:10.1101/lm.78804

Bowman RE, Ferguson D, Luine VN. 2002. Effects of chronic restraint stress and estradiol on open field activity, spatial memory, and monoaminergic neurotransmitters in ovariectomized rats. Neuroscience 113: 401-410. doi:10.1016/S0306-4522(02)00156-2

Brembs B, Heisenberg M. 2001. Compound conditioning in Drosophila.

Breslau N, Chilcoat HD, Kessler RC, Davis GC. 1999. Previous exposure to trauma and PTSD effects of subsequent trauma: results from the detroit area survey of trauma. Am J Psychiatry 156: 902-907. doi:10.1176/ajp .156 .6 .902

Bryant RA. 2017a. Acute stress disorder. Curr Opin Psychol 14: 127-131. doi:10.1016/j.copsyc.2017.01.005

Bryant RA. 2017b. Posttraumatic stress disorder. Sci Cogn Behav Ther 319-336. doi:10.1016/B978-0-12-803457-6.00013-1

Bryant RA, Felmingham K, Kemp A, Das P, Hughes G, Peduto A, Williams L. 2008. Amygdala and ventral anterior cingulate activation predicts treatment response to cognitive behaviour therapy for post-traumatic stress disorder. Psychol Med 38: 555-561. doi:10.1017/ S0033291707002231

Chiba S, Numakawa T, Ninomiya M, Richards MC, Wakabayashi C, Kunugi H. 2012. Chronic restraint stress causes anxiety- and depression-like behaviors, downregulates glucocorticoid receptor expression, and attenuates glutamate release induced by brain-derived neurotrophic factor in the prefrontal cortex. Prog Neuro Psychopharmacol Biol Psychiatry 39: 112-119. doi:10.1016/j.pnpbp.2012.05.018

Conrad CD, Ledoux JE, Magariños a M, Mcewen BS. 1999. Repeated restraint stress facilitates fear conditioning independently of causing hippocampal CA3 dendritic atrophy. Behav Neurosci 113: 902-913. doi:10.1037/0735-7044.113.5.902

Conrad CD, Ortiz JB, Judd JM. 2017. Chronic stress and hippocampal dendritic complexity: methodological and functional considerations. Physiol Behav 176: 66-81. doi:10.1016/j.physbeh.2016.11.017

Cordero MI, Venero C, Kruyt ND, Sandi C. 2003. Prior exposure to a single stress session facilitates subsequent contextual fear conditioning in rats: evidence for a role of corticosterone. Horm Behav 44: 338-345. doi:10 .1016/S0018-506X(03)00160-0

D'Aquila PS, Brain P, Willner P. 1994. Effects of chronic mild stress on performance in behavioural tests relevant to anxiety and depression. Physiol Behav 56: 861-867. doi:10.1016/0031-9384(94)90316-6 
Daskalakis NP, Yehuda R, Diamond DM. 2013. Animal models in translational studies of PTSD. Psychoneuroendocrinology 38: 1895-1911. doi:10.1016/j.psyneuen.2013.06.006

Eiland L, McEwen BS. 2012. Early life stress followed by subsequent adult chronic stress potentiates anxiety and blunts hippocampal structural remodeling. Hippocampus 22: 82-91. doi:10.1002/hipo.20862

Fidell LS, Tabachnick BG. 2007. Experimental design using ANOVA. Duxbury, Belmont, CA.

Foilb AR, Bals J, Sarlitto MC, Christianson JP. 2018. Sex differences in fear discrimination do not manifest as differences in conditioned inhibition. Learn Mem 25: 49-53. doi:10.1101/lm.045500.117

Gewirtz JC, Davis M. 2000. Using Pavlovian higher-order conditioning paradigms to investigate the neural substrates of emotional learning and memory. Learn Mem 7: 257-266. doi:10.1101/lm.35200

Ghiglieri O, Gambarana C, Scheggi S, Tagliamonte A, Willner P, De Montis MG. 1997. Palatable food induces an appetitive behaviour in satiated rats which can be inhibited by chronic stress. Behav Pharmacol 8: 619-628. doi:10.1097/00008877-199711000-00018

Grillon C, Morgan CA, Davis M, Southwick SM. 1998. Effect of darkness on acoustic startle in Vietnam veterans with PTSD. Am J Psychiatry 155: 812-817.

Hoffman AN, Krigbaum AM, Ortiz JB, Mika A, Hutchinson KM, Bimonte-Nelson HA, Conrad CD. 2011. Recovery after chronic stress within spatial reference and working memory domains: correspondence with hippocampal morphology. Eur J Neurosci 34: 1023-1030. doi:10 $.1111 / \mathrm{j} .1460-9568.2011 .07820 . x$

Hoffman AN, Lorson NG, Sanabria F, Olive MF, Conrad CD. 2014. Chronic stress disrupts fear extinction and enhances amygdala and hippocampal Fos expression in an animal model of post-traumatic stress disorder. Neurobiol Learn Mem 112: 139-147. doi:10.1016/j.nlm.2014.01.018

Hoffman AN, Parga A, Paode PR, Watterson LR, Nikulina EM, Hammer RP, Conrad CD. 2015. Chronic stress enhanced fear memories are associated with increased amygdala zif268 mRNA expression and are resistant to reconsolidation. Neurobiol Learn Mem 120: 61-68. doi:10.1016/j.nlm .2015.02.004

Hoge CW, Warner CH. 2014. Estimating PTSD prevalence in US veterans: considering combat exposure, PTSD checklist cutpoints, and DSM-5. J Clin Psychiatry 75: e1439-e1441. doi:10.4088/JCP.14com09616

Huynh TN, Krigbaum AM, Hanna JJ, Conrad CD. 2011. Sex differences and phase of light cycle modify chronic stress effects on anxiety and depressive-like behavior. Behav Brain Res 222: 212-222. doi:10.1016/j bbr.2011.03.038

Izquierdo A, Wellman CL, Holmes A. 2006. Brief uncontrollable stress causes dendritic retraction in infralimbic cortex and resistance to fear extinction in mice. J Neurosci 26: 5733-5738. doi:10.1523/JNEUROSCI .0474-06.2006

Jacobs NS, Cushman JD, Fanselow MS. 2010. The accurate measurement of fear memory in Pavlovian conditioning: resolving the baseline issue. J Neurosci Methods 190: 235-239. doi:10.1016/j.jneumeth.2010.04.029

Ji J, Maren S. 2007. Hippocampal involvement in contextual modulation of fear extinction. Hippocampus 17: 749-758. doi:10.1002/hipo.20331

Jovanovic T, Kazama A, Bachevalier J, Davis M. 2012. Impaired safety signal learning may be a biomarker of PTSD. Neuropharmacology 62: 695-704. doi:10.1016/j.neuropharm.2011.02.023

Katz M, Liu C, Schaer M, Parker KJ, Ottet MC, Epps A, Buckmaster CL, Bammer R, Moseley ME, Schatzberg AF, et al. 2009. Prefrontal plasticity and stress inoculation-induced resilience. Dev Neurosci 31: 293-299. doi:10.1159/000216540

Kleen JK, Sitomer MT, Killeen PR, Conrad CD. 2006. Chronic stress impairs spatial memory and motivation for reward without disrupting motor ability and motivation to explore. Behav Neurosci 120: 842-851. doi:10 .1037/0735-7044.120.4.842

Knox D, George SA, Fitzpatrick CJ, Rabinak CA, Maren S, Liberzon I. 2012 Single prolonged stress disrupts retention of extinguished fear in rats. Learn Mem 19: 43-49. doi:10.1101/lm.024356.111

Luine V, Villegas M, Martinez C, McEwen BS. 1994. Repeated stress causes reversible impairments of spatial memory performance. Brain Res 639: 167-170. doi:10.1016/0006-8993(94)91778-7

Lyons DM, Parker KJ, Katz M, Schatzberg AF. 2009. Developmental cascades linking stress inoculation, arousal regulation, and resilience. Front Behav Neurosci 3: 32. doi:10.3389/neuro.08.032.2009

Lyons DM, Parker KJ, Schatzberg AF. 2010. Animal models of early life stress: implications for understanding resilience. Dev Psychobiol 52: 616-624. doi:10.1002/dev.20500

Majchrzak M, Ferry B, Marchand AR, Herbeaux K, Seillier A, Barbelivien A. 2006. Entorhinal cortex lesions disrupt fear conditioning to background context but spare fear conditioning to a tone in the rat. Hippocampus 16: 114-124. doi:10.1002/hipo.20138

McGuire J, Herman JP, Horn PS, Sallee FR, Sah R. 2010. Enhanced fear recall and emotional arousal in rats recovering from chronic variable stress. Physiol Behav 101: 474-482. doi:10.1016/j.physbeh.2010.07.013
McLaughlin KJ, Gomez JL, Baran SE, Conrad CD. 2007. The effects of chronic stress on hippocampal morphology and function: an evaluation of chronic restraint paradigms. Brain Res 1161: 56-64. doi:10.1016/j .brainres.2007.05.042

Mikics E, Baranyi J, Haller J. 2008. Rats exposed to traumatic stress bury unfamiliar objects: a novel measure of hyper-vigilance in PTSD models? Physiol Behav 94: 341-348. doi:10.1016/j.physbeh.2008.01.023

Milad MR, Orr SP, Lasko NB, Chang Y, Rauch SL, Pitman RK. 2008. Presence and acquired origin of reduced recall for fear extinction in PTSD: results of a twin study. J Psychiatr Res 42: 515-520. doi:10.1016/j.jpsychires .2008.01.017

Milad MR, Pitman RK, Ellis CB, Gold AL, Shin LM, Lasko NB, Zeidan MA, Handwerger K, Orr SP, Rauch SL. 2009. Neurobiological basis of failure to recall extinction memory in posttraumatic stress disorder. Biol Psychiatry 66: 1075-1082. doi:10.1016/j.biopsych.2009.06.026

Miracle AD, Brace MF, Huyck KD, Singler SA, Wellman CL. 2006. Chronic stress impairs recall of extinction of conditioned fear. Neurobiol Learn Mem 85: 213-218. doi:10.1016/j.nlm.2005.10.005

Ortiz JB, Taylor SB, Hoffman AN, Campbell AN, Lucas LR, Conrad CD. 2015. Sex-specific impairment and recovery of spatial learning following the end of chronic unpredictable restraint stress: potential relevance of limbic GAD. Behav Brain Res 282: 176-184. doi:10.1016/j.bbr.2014.12 .051

Radulovic J, Kammermeier J, Spiess J. 1998. Generalization of fear responses in C57BL/6N mice subjected to one- trial foreground contextual fear conditioning. Behav Brain Res 95: 179-189. doi:10.1016/S0166-4328 (98)00039-4

Rau V, DeCola JP, Fanselow MS. 2005. Stress-induced enhancement of fear learning: an animal model of posttraumatic stress disorder. Neurosci Biobehav Rev 29: 1207-1223. doi:10.1016/j.neubiorev.2005.04.010

Rauhut AS, Mcphee JE, Ayres JJB. 1999. Blocked and overshadowed stimuli are weakened in their ability to serve as blockers and second-order reinforcers in Pavlovian fear conditioning. J Exp Psychol Anim Behav Process 25: 45-67. doi:10.1037/0097-7403.25.1.45

Rescorla RA. 1969. Pavlovian conditioned inhibition. Psychol Bull 72: 77-94. doi:10.1037/h0027760

Rizley RC, Rescorla RA. 1972. Associations in second-order conditioning and sensory preconditioning. J Comp Physiol Psychol 81: 1-11. doi:10 $.1037 /$ h0033333

Rothbaum BO, Davis M. 2003. Applying learning principles to the treatment of post-trauma reactions. Ann N Y Acad Sci 1008: 112-121. doi:10.1196/ annals.1301.012

Sareen J. 2014. Posttraumatic stress disorder in adults: impact, comorbidity, risk factors, and treatment. Can J Psychiatry 59: 460-467. doi:10.1177/ 070674371405900902

Schnurr PP, Lunney CA, Sengupta A. 2004. Risk factors for the development versus maintenance of posttraumatic stress disorder. J Trauma Stress 17: 85-95. doi:10.1023/B:JOTS.0000022614.21794.f4

Song L, Che W, Min-wei W, Murakami Y, Matsumoto K. 2006. Impairment of the spatial learning and memory induced by learned helplessness and chronic mild stress. Pharmacol Biochem Behav 83: 186-193. doi:10.1016/ j.pbb.2006.01.004

Sousa N, Lukoyanov N V, Madeira MD, Almeida OFX, Paula-Barbosa MM. 2000. Reorganization of the morphology of the hippocampal neurites and synapses after stress-induced damage correlates with behavioral improvement. Neuroscience 97: 253-266. doi:10.1016/S0306-4522(00) 00050-6

Urcelay GP, Miller RR. 2009. Potentiation and overshadowing in Pavlovian fear conditioning NIH public access. J Exp Psychol Anim Behav Process 35: 340-356. doi:10.1037/a0014350

van Dijken HH, Mos J, van der Heyden JAM, Tilders FJH. 1992. Characterization of stress-induced long-term behavioural changes in rats: evidence in favor of anxiety. Physiol Behav 52: 945-951. doi:10 1016/0031-9384(92)90375-C

Vyas A, Pillai AG, Chattarji S. 2004. Recovery after chronic stress fails to reverse amygdaloid neuronal hypertrophy and enhanced anxiety-like behavior. Neuroscience 128: 667-673. doi:10.1016/j.neuroscience.2004 .07 .013

Wessa M, Flor H. 2007. Failure of extinction of fear responses in posttraumatic stress disorder: evidence from second-order conditioning. Am J Psychiatry 164: 1684-1692. doi:10.1176/appi.ajp.2007.07030525

Xue C, Ge Y, Tang B, Liu Y, Kang P, Wang M. 2015. A meta-analysis of risk factors for combat-related PTSD among military personnel and veterans. PLoS One 10: 120270. doi:10.1371/journal.pone.0120270

Yehuda R, LeDoux J. 2007. Response variation following trauma: a translational neuroscience approach to understanding PTSD. Neuron 56: 19-32. doi:10.1016/j.neuron.2007.09.006

Received October 18, 2019; accepted in revised form June 10, 2020. 


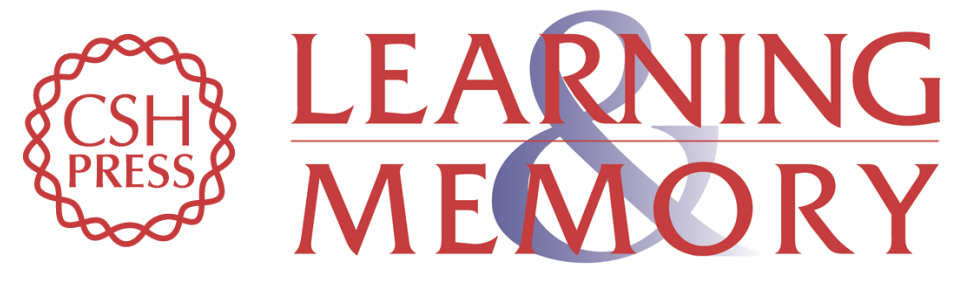

\section{Chronic stress has lasting effects on improved cued discrimination early in extinction}

Jessica M. Judd, Elliot A. Smith, Jinah Kim, et al.

Learn. Mem. 2020, 27:

Access the most recent version at doi:10.1101/lm.051060.119

\section{Supplemental http://learnmem.cshlp.org/content/suppl/2020/07/09/27.8.319.DC1 Material}

References This article cites 63 articles, 4 of which can be accessed free at: http://learnmem.cshlp.org/content/27/8/319.full.html\#ref-list-1

Creative This article is distributed exclusively by Cold Spring Harbor Laboratory Press for the Commons first 12 months after the full-issue publication date (see

License http://learnmem.cshlp.org/site/misc/terms.xhtml). After 12 months, it is available under a Creative Commons License (Attribution-NonCommercial 4.0 International), as described at http://creativecommons.org/licenses/by-nc/4.0/.

Email Alerting Receive free email alerts when new articles cite this article - sign up in the box at the Service top right corner of the article or click here. 